\title{
Bio-based epoxy resin toughening with cashew nut shell liquild-derived resin
}

\section{Anthony Maiorana BS}

Doctoral Candidate, New York State Center for Polymer Synthesis, Department of Chemistry and Chemical Biology, Rensselaer Polytechnic Institute, Troy, NY, USA

\section{Liyun Ren PhD}

Postdoctoral Research Scientist, Department of Materials Science and Engineering, Rensselaer Polytechnic Institute, Troy, NY, USA

\section{Giada Lo Re PhD}

Postdoctoral Research Scientist, Centre d'Innovation et de Recherche en MAtériaux Polymères CIRMAP, Service des Matériaux Polymères et Composites, University of Mons, Mons, Belgium

\section{Stephen Spinella PhD}

Postdoctoral Research Scientist, New York State Center for Polymer Synthesis, Department of Chemistry and Chemical Biology, Rensselaer Polytechnic Institute, Troy, NY, USA

Centre d'Innovation et de Recherche en MAtériaux Polymères CIRMAP, Service des Matériaux Polymères et Composites, University of Mons, Mons, Belgium

\section{Chang Y. Ryu PhD}

Professor, New York State Center for Polymer Synthesis, Department of Chemistry and Chemical Biology, Rensselaer Polytechnic Institute, Troy, NY, USA

\section{Philippe Dubois PhD}

Professor, Centre d'Innovation et de Recherche en MAtériaux Polymères CIRMAP, Service des Matériaux Polymères et Composites, University of Mons, Mons, Belgium

Richard A. Gross PhD*

Professor, New York State Center for Polymer Synthesis, Department of Chemistry and Chemical Biology, Rensselaer Polytechnic Institute, Troy, NY, USA

With the combinations of diglycidyl ether diphenolate methyl ester (DGEDP-Me), a rigid high-viscosity bio-based epoxy resin and a flexible lower viscosity epoxy resin from cashew nut shell liquid (NC-514), resin viscosity was controlled and important improvements were realized in cured epoxy resin toughness relative to the neat resins. The viscosities of DGEDP-Me/NC-514 mixtures varied from 660 to 26 Pa.s, and curing was performed using stoichiometric amounts of a diamine cross-linker. Using scanning electron microscopy analysis of fractured surfaces, the cured materials were shown to be one-phase. Furthermore, all resin compositions were transparent and have one alpha transition temperature, confirming resin miscibility. Storage modulus values for cured thermosets range from 3000 to $1000 \mathrm{MPa}$, and alpha transition temperatures varied linearly $\left(158\right.$ to $\left.27^{\circ} \mathrm{C}\right)$ as a function of the epoxy resin composition. Oscillatory rheology at different weight percentages of the flexible and rigid epoxy resin components was used to determine the average molecular weight between cross-links which was correlated to material toughness. Relative to the neat high-viscosity resin, 1:1 wt/wt mixtures of the rigid and flexible epoxy resin components gave increases in the impact strength and mode I fracture toughness of 136 and $66 \%$, respectively. Higher percentages of the flexible epoxy resin resulted in decreased toughness.

\section{Introduction}

Epoxy resins are building blocks used to form a versatile class of thermoset polymers. They can be cured under a wide range of conditions and exist as solids or liquids at room temperature. Liquid epoxy resins are ideal for manufacturing large one-piece structural composites such as wind turbine blades and car frames. ${ }^{1}$ Higherviscosity liquid epoxy resins also find uses as structural adhesives for wind turbine blades, car frames and electronics. Aside from composites, liquid and solid epoxy resins also find a wide variety of uses as protective coatings due to their anticorrosive nature and good adhesion to metal substrates. ${ }^{2}$ Epoxy resins can be designed such that after curing they result in thermosets with high modulus and glass transition temperatures. However, these thermosets may possess low impact resistance and brittle fracture. ${ }^{3}$

Bisphenol A (BPA) and, subsequently, the diglycidyl ether of bisphenol A (DGEBA), is currently used for the preparation of a versatile family of high-performance cured epoxy resins. 
However, BPA is derived from petroleum which is not sustainable. Furthermore, BPA is linked to myriad health problems such as causing cancer and obesity and disrupting the endocrine system. ${ }^{4-9}$ Heightened public concerns over BPA's potential health problems along with its production from petroleum have stimulated academic and industrial research to develop safe and sustainable BPA alternatives. ${ }^{710}$

Diglycidyl isosorbide is a sugar-derived epoxy resin that, after curing, gives excellent mechanical properties with a glass transition temperature that is similar to DGEBA-based thermosets. However, their synthesis is challenging since isosorbide has two secondary hydroxyl groups and corresponding thermosets have low water resistance. ${ }^{11}$ Cured tetraglycidyl gallate derived from tannins exceeds the thermomechanical properties of DGEBA-based thermosets. Nevertheless, the high epoxide functionality of tetraglycidyl gallate gives thermosets with a high cross-linking density which can result in brittle materials. ${ }^{12,13}$ Epoxy resins derived from cardanol, a by-product of the cashew nut industry, have also received attention from both academic and industrial research groups. ${ }^{14-18}$ Relative to DGEBA, cured cardanol-based epoxy resins possess a low modulus and glass transition temperature. ${ }^{16}$ However, cross-linked materials from cardanol epoxy resins retain good flexibility. Consequently, they may be useful components in bio-based epoxy resin mixtures that provide toughening. Previous work demonstrated that combining DGEBA with the glycidyl ether of cardanol increased cured thermoset flexibility but had little to no effect in changing the material's impact strength. ${ }^{17}$ The Cardolite Corporation sells a commercial flexible epoxy resin under the trade name Cardolite $\mathrm{NC}-514$ (NC-514). Its thermomechanical and chemical properties are published. ${ }^{16}$ Despite excellent works on the synthesis and materials characterization of the bio-based epoxy resin alternatives to those from BPA, the viscosities of these resins are relatively undiscussed despite the importance of viscosity to epoxy resin processing and applications.

The resistance to crack growth and fracture is a measure of a material's toughness, and epoxy resins are known to be brittle due to being tightly cross-linked. ${ }^{3}$ Consequently, important work has been performed to toughen cured epoxy resins. ${ }^{18}$ Rubber toughening, also known as phase separation toughening, involves incorporation of a rubbery phase within cured epoxy resins. The rubbery phase is derived from additives such as lowmolecular-weight rubbers, ${ }^{19}$ diblock copolymers, ${ }^{20}$ epoxidized vegetable oils ${ }^{21}$ and low-molecular-weight glycidyl ethers. ${ }^{22}$ Phase separation toughening can reduce crack propagation when the majority of the stress can be transferred to the rubbery phase. When high levels of the rubbery phase are required, rubber toughening may also result in materials with reduced modulus, lower glass transition temperatures and increased resin viscosities. ${ }^{18}$ Diblock copolymer toughening of epoxy resins ${ }^{23}$ enables toughening of thermoset systems without significant sacrifices in the modulus or glass transition temperature. ${ }^{24}$
Further, by altering diblock copolymer structure by manipulating the chain segment block lengths, the toughening characteristics of the resulting thermoset materials can be controlled. ${ }^{25-27}$ However, the synthesis of diblock copolymers as toughening agents can be costly to manufacture on a large scale.

Herein, the authors explore an approach to toughen cured epoxy resins that encompasses altering the thermoset polymer backbone by combining both flexible and rigid epoxy resins that results in single-phase copolymers. Varying the molecular weight between cross-links has been linked to toughening in both mode I fracture and impact resistance. ${ }^{28-31}$ However, the use of high-molecular-weight epoxy resins with low epoxide functionality presents challenges in processing as increasing the molecular weight before curing results in solid epoxy resins that requires high processing temperatures or the use of organic solvents. Additionally, increasing the molecular weight between cross-links can dramatically reduce the glass transition temperatures of the resulting thermosets, limiting their use in high-performance applications. To date, a systematic study of miscible combinations of rigid and flexible epoxy resins is unexplored.

This paper tests the hypothesis that extending the molecular weight between cross-links of a rigid epoxy resin by incorporating a flexible epoxy resin component will result in thermosets with improved toughness. A series of thermoset resins were prepared from different ratios of diglycidyl ether diphenolate methyl ester (DGEDP-Me), a high-viscosity bio-based epoxy resin recently reported by some of the present authors, ${ }^{32}$ and a flexible lowerviscosity epoxy cardanol resin prepared from cashew nut shell liquid (NC-514) (Scheme 1). ${ }^{16}$ Studies are described that provide an understanding of how the DGEDP-Me/NC-514 composition and temperature influence resin viscosity and gelation. Curing of epoxy resins was performed with nearly stoichiometric quantities of isophorone diamine at different temperatures to gain insights into how these variables alter the gel point and minimum viscosity. To further the knowledge on structureproperty relationships of the cured resins, characterizations were performed by dynamic mechanical analysis, thermal gravimetric analysis, parallel plate oscillatory rheology, three-point bending and notched Izod impact testing. The results of this work provide important insights into the design principles that determine epoxy resin viscosity and the construction of tough high-performance thermoset materials from epoxy resins.

\section{Experimental}

\subsection{Materials}

Cardolite NC-514 (NC-514) was supplied as a gift from the Cardolite Corporation and was used as received. Isophorone diamine (IPDA) was purchased from Sigma Aldrich and used as received. The DGEDP-Me was prepared as previously reported. ${ }^{32}$ 


\subsection{Preparation of cured epoxy materials for testing} Epoxide equivalent weights of the neat resins were taken from previously reported results ${ }^{32}$ or the manufacture's specification. Weights of reaction components were calculated by using the epoxide equivalent weight (EEW) and the amine hydrogen equivalent weight (AHEW), which were calculated by Equations 1 and 2, respectively. Values of EEW and AHEW were placed into Equation 3 to obtain the parts by weight of diamine per hundred parts resin (phr). ${ }^{3}$

1. EEW of mix $=\frac{\text { Total weight }}{\frac{\text { Weight of resin } \mathrm{A}}{\text { EEW of } \mathrm{A}}+\frac{\text { Weight of resin } \mathrm{B}}{\text { EEW of } \mathrm{B}}}$

\section{AHEW $=\frac{\text { Molecular weight of amine }}{\text { Number of active hydrogens }}$}

3. $\mathrm{phr}=\frac{\mathrm{AHEW} \times 100}{\mathrm{EEW}}$

An example would be if phr is 30 , then $30 \mathrm{~g}$ of diamine hardener would be needed for $100 \mathrm{~g}$ of epoxy resin. Epoxy resins were vigorously mixed by hand with a metal spatula with the appropriate amount of IPDA until the mixture appeared homogenous. The mixed resins were then degassed by centrifugation in a syringe (3000 rpm, $2 \mathrm{~min}$ ) to remove air bubbles due to mixing. The resins were then transferred via syringe into stainless steel molds coated with polytetrafluoroethylene mold release agent. The four different mold geometries used were: rectangular dual cantilever bars $(35 \times 12 \times 3 \mathrm{~mm})$, ASTM D256 Izod Impact bars $(64 \times 12.7 \times 3.2 \mathrm{~mm})$, rheology discs $(25 \times 2 \mathrm{~mm})$ and rectangular three-point bend bars $(35 \times 8 \times 4 \mathrm{~mm})$. The method of resin curing was adapted from a literature procedure. ${ }^{33}$ In summary, the resins were maintained under ambient conditions in the molds for $16 \mathrm{~h}$ after which they were compression molded for $4 \mathrm{~h}$ at $80^{\circ} \mathrm{C}$ with two metric tons of applied pressure and then $4 \mathrm{~h}$ at $160^{\circ} \mathrm{C}$ without any release of pressure. For chemorheology, samples were mixed with IPDA as previously described and were then placed on the rheometer to minimize effects of cold curing.

\subsection{Dynamic mechanical analysis}

A dynamic mechanical analysis (DMA) was performed using TA Q800 from TA Instruments (New Castle, DE). A dual cantilever mode with an amplitude of $10 \mu \mathrm{m}$ was used to determine the storage modulus $\left(E^{\prime}\right)$ and glass transition temperature (determined from the peak of the loss modulus $\left(E^{\prime \prime}\right)$ by scanning at $2^{\circ} \mathrm{C} / \mathrm{min}$ from 0 to $200^{\circ} \mathrm{C}$. All DMA tests were repeated at least three times.

\subsection{Rheology}

The viscosity of the different resins and their mixtures was determined by steady shear experiments at 25, 30, 40, 50 and $60^{\circ} \mathrm{C}$ using a TA Instruments AR-G2 rheometer equipped with 25-mm-diameter parallel plates. The shear rate ranged from 1 to
$100 / \mathrm{s}$ under the steady shear flow with an equilibration time of $1 \mathrm{~min}$ and a sample gap of $1 \mathrm{~mm}$ at each temperature. The viscosity was reported as an average from the Newtonian region. The average molecular weight between cross-links was determined using a TA Instruments AR-G2 rheometer by a literature method. ${ }^{32}$ For chemorheology, dynamic shear experiments were performed using a TA Instruments AR-G2 rheometer equipped with 8-mm-diameter parallel plates. Temperatures were ramped at $5^{\circ} \mathrm{C} / \mathrm{min}$ at a frequency of $1 \mathrm{rad} / \mathrm{s}$ to the isothermal time sweep. Each isothermal cure was monitored in multifrequency mode from 1 to $15 \mathrm{rad} / \mathrm{s}$ with a total of five frequencies operating at $0.1 \%$ strain. Gel times are measured as the time from the start of the test till momentary frequency independence of the $\tan \delta .^{34}$

\subsection{Thermogravimetric analysis}

The thermal stability of the prepared resins was studied by thermogravimetric analysis using a TA Instruments Q50 with an alumina pan. The samples were about $10 \mathrm{mg}$ each and were run from room temperature to $800^{\circ} \mathrm{C}$ at a heating rate of $10^{\circ} \mathrm{C} / \mathrm{min}$ under constant $\mathrm{N}_{2}$ flow.

\subsection{Differential scanning calorimetry}

Differential scanning calorimetry (DSC) was conducted on cured samples and diphenolate esters using a TA Instruments Q2000 with $T_{\text {zero }}$ aluminum pans at a scanning rate of $10^{\circ} \mathrm{C} / \mathrm{min}$ from -80 to $200^{\circ} \mathrm{C}$ under constant $\mathrm{N}_{2}$ flow. Modulated DSC was used at a modulation of $1^{\circ} \mathrm{C} / \mathrm{min}$ from 25 to $210^{\circ} \mathrm{C}$ with $T_{\text {zero }}$ aluminum pans under constant $\mathrm{N}_{2}$ flow.

\subsection{Fourier transform infrared spectroscopy}

Experiments were performed by attenuated total reflectance using a Perkin Elmer Spectrum One with a ZnSe Flat Plate $45^{\circ}$ horizontal attenuated total reflectance sampling accessory. Spectra were obtained by scanning from 450 to $4000 \mathrm{~cm}^{-1}$. No baseline correction or other data manipulation techniques were employed.

\subsection{Notched Izod impact}

Samples were notched and tested on an Izod impact tester under ambient conditions after being equilibrated at $50 \%$ relative humidity and ambient temperature for $24 \mathrm{~h}$. Results are reported as an average of five runs with error bars representing standard deviation.

\subsection{Single edge notched bending test}

The mode I fracture toughness $\left(K_{\mathrm{IC}}\right)$ and fracture energy $\left(G_{\mathrm{IC}}\right)$ test was performed with an Instron 4205 universal tester. Single edge notched bending specimens were molded to be $35 \times 4 \times 8 \mathrm{~mm}$ in accordance with the ASTM D5045-99. The cross-head speed for the test was $1 \mathrm{~mm} / \mathrm{min}$. A diamond saw was used to machine the notch on the sample. Subsequently, a fresh rotary razor blade is used to introduce a pre-crack with good control of the brittle crack. 
The depth of the pre-crack and the notch were well controlled within an error of $\pm 20 \mu \mathrm{m}$. Results are reported as an average of three runs with error bars representing standard deviation.

\subsection{Scanning electron microscopy}

The fractured surfaces from the Izod impact test were analyzed by using a Philips XL20 scanning electron microscope operating at $5 \cdot 0 \mathrm{kV}$ with no stage bias and a $3 \mathrm{~nm}$ platinum sputter coating.

\subsection{Small-angle X-ray scattering}

The polymer samples were analyzed by using a Bruker Nanostar-U with a turbo rotating anode X-ray source equipped with a HI-STAR detector and an image plate for simultaneous small angle X-ray scattering/wide angle $\mathrm{X}$-ray scattering measurements.

\section{Results and discussion}

\subsection{Steady shear rheology: temperature dependence of viscosity}

The viscosity as a function of temperature and composition of mixtures consisting of DGEDP-Me/NC-514 was measured by rotational rheology (Figure 1). Relative to pure DGEDP-Me, a blend consisting of DGEDP-Me and $50 \% \mathrm{NC}-514$ at $25^{\circ} \mathrm{C}$ has a viscosity that is lower by about an order of magnitude (neat resins range from 660 to $26 \mathrm{~Pa}$.s). Furthermore, the 50\% combination is a Newtonian fluid over the range of shear rates tested (Figure 1(a)). Since both neat DGEDP-Me and a solution with $20 \%$ NC-514 are not Newtonian fluids over the identical range of shear rates at $25^{\circ} \mathrm{C}, 50 \% \mathrm{NC}-514$ is sufficient to disrupt the intermolecular forces responsible for this shear-thinning behavior. Measurement of viscosity at temperatures above $25^{\circ} \mathrm{C}$ (up to $60^{\circ} \mathrm{C}$ ) results in further reductions in viscosity. Over this temperature range, the viscosity of neat DGEDP-Me resins is over two orders of magnitude lower (660 to 4 Pa.s). The viscosity of a neat DGEDP-Me at $30^{\circ} \mathrm{C}$ is $63 \%$ lower than that at $25^{\circ} \mathrm{C}$. This indicates that the origin of neat DGEDP-Me's high viscosity is primarily weak intermolecular interactions as had previously been postulated. ${ }^{32}$ Likewise, neat DGEDP-Me viscosity at 40 and $50^{\circ} \mathrm{C}$ decreased by 94 and $99 \%$, respectively, relative to the viscosity at $25^{\circ} \mathrm{C}$. Resin viscosities were repeatable after being tested at $60^{\circ} \mathrm{C}$ indicating that, under these conditions, the epoxy resins are chemically stable. The large temperature-dependence of DGEDP-Me viscosity is important as it provides a route for high-temperature processing of epoxy resins with latent cross-linking agents that is of interest for future studies because of its use in infusion molding.

To understand further the intermolecular interactions of epoxy resin molecules, plots of the natural log of the Newtonian viscosity as a function of 1000/T were constructed, and the data for each ratio of DGEDP-Me/NC-514 was fitted to the Arrhenius model for fluids (Figure 1(b)). The Arrhenius relationship is shown in Equation 4 , where $\eta$ is equal to viscosity $\eta_{\mathrm{o}}$ is a coefficient, $E_{\mathrm{A}}$ is the activation energy for flow, $R$ is the universal gas constant and $T$ is temperature in Kelvin. Table 1 lists values of experimentally determined activation energies, slopes $\left(E_{\mathrm{A}} / R\right)$ of plots in Figure 1 (b) and EEW values calculated from Equation 1.

4. $\quad \eta=\eta_{0} \mathrm{e}^{E_{\mathrm{A}} / R T}$

These values provide insight into the strength of intermolecular interactions which are responsible for resin viscosity. Consequently, they establish the amount of energy and the corresponding processing conditions (e.g. shear force, temperature) required for epoxy resin flow.

Viscosity reduction achieved by mixing DGEDP-Me with NC-514 occurs through disruption of DGEDP-Me intermolecular interactions. Furthermore, viscosity reduction of DGEDP-Me/ NC-514 epoxy resin mixtures becomes less temperature-dependent with increasing NC-514 content. The NC-514 viscosity is higher than expected based on the molecular structure. This is due to the presence in NC-514 of oligomers that originate from the synthesis of the resin in addition to the ideal structure shown in Scheme 1. The coexistence of oligomers is discussed in detail elsewhere. ${ }^{16}$

\subsection{Dynamic shear rheology: chemorheology for gelation}

The temperature ramp $\left(5^{\circ} \mathrm{C} / \mathrm{min}\right)$ to the desired cure temperature presents a realistic simulation for the curing of the epoxy resins as cure temperatures are typically not reached instantaneously. During the temperature ramp, all the epoxy compositions containing stoichiometric amounts of isophorone diamine reached

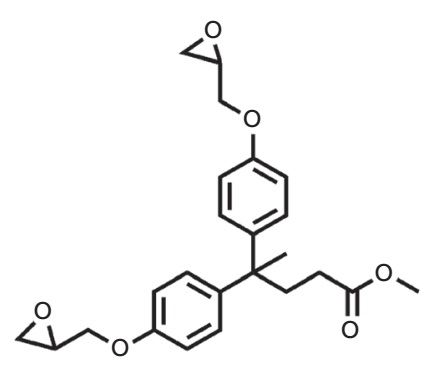

DGEDP-methyl ester

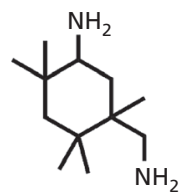

Isophorone diamine

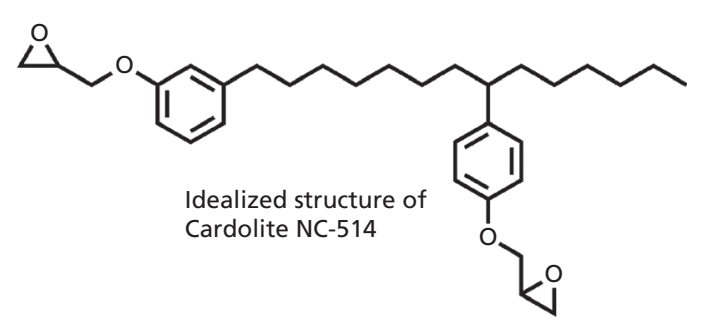

Scheme 1. Structures of diglycidyl ether diphenolate methyl ester (DGEDP-Me), ${ }^{32}$ diglycidyl ether of cardanol from cashew nut shell liquid (NC-514) ${ }^{16}$ and isophorone diamine used for cross-linking. 


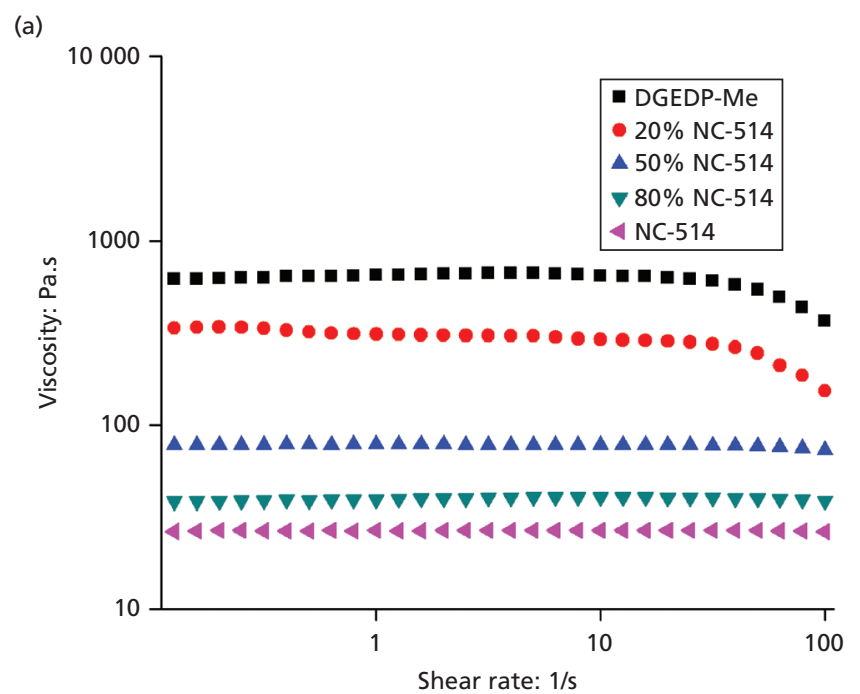

Figure 1. (a) Viscosity as a function of wt $\% \mathrm{NC}-514$ at $25^{\circ} \mathrm{C}$. (b) First-order exponential fitting of Newtonian viscosity dependence as a function of temperature

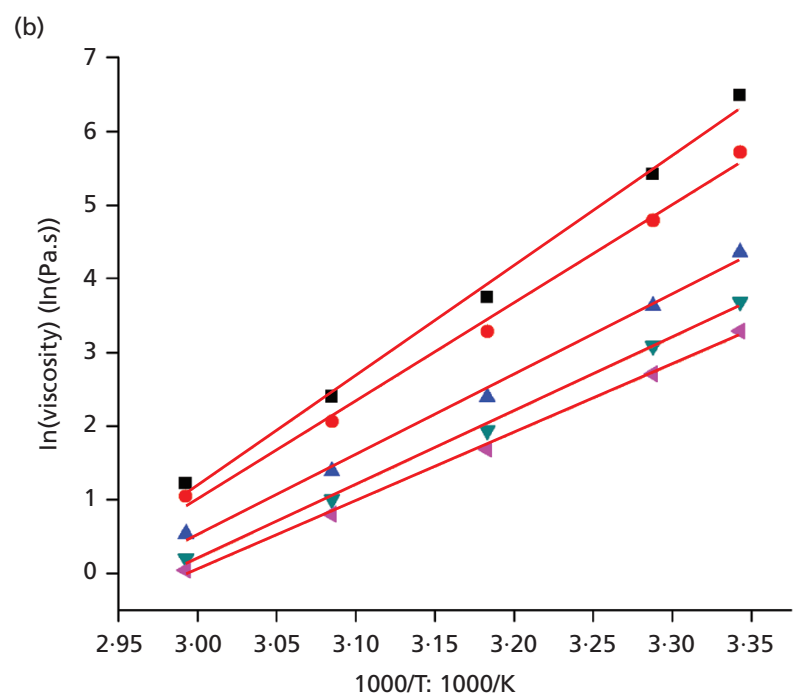

\begin{tabular}{lccc} 
& $\boldsymbol{E}_{\mathrm{A}} / \mathbf{R}$ & $\boldsymbol{E}_{\mathrm{A}}: \mathbf{k J} / \mathbf{m o l}$ & $\begin{array}{c}\text { EEW: } \mathbf{g} / \\
\text { eq } \mathbf{~ m o l}\end{array}$ \\
DGEDP-Me & 14.9 & 124 & $215^{\mathrm{a}}$ \\
20\% NC-514 & $13 \cdot 3$ & 110 & 242 \\
$50 \%$ NC-514 & $10 \cdot 9$ & 90 & 299 \\
$80 \%$ NC-514 & $10 \cdot 0$ & 83 & 390 \\
$100 \%$ NC-514 & 93.0 & 77 & $490^{\mathrm{b}}$ \\
\hline
\end{tabular}

aFrom previously reported data. ${ }^{32}$

bFrom the supplier's analysis.

The activation energy of flow for each resin composition ranges from $124 \mathrm{~kJ} / \mathrm{mol}$ (neat DGEDP-Me) to $77 \mathrm{~kJ} / \mathrm{mol}$ (neat NC-514).

Table 1. Activation energy for flow of the epoxy resin mixtures and the slope used to determine the activation energy from Figure 1(b)

their minimum viscosity at $40^{\circ} \mathrm{C}$. Once the resins reached a predetermined isothermal temperature $\left(60,70,80,90\right.$ and $\left.100^{\circ} \mathrm{C}\right)$, the rheometer was operated in a multifrequency mode to determine the gel point under the designated isothermal condition as the momentary frequency independence of the $\tan \delta .^{34}$ The gel point is indicative of the onset of infinite network formation and offers information on the reactivity of the resin mixture. Figure 2 displays gel times as a function of temperature for neat DGEDP-Me, NC-514 and a 1:1 (wt/wt) DGEDP-Me/NC-514 mixture.

Epoxy resin network formation is expected to be highly dependent on its viscosity, epoxide content, and cross-linker reactivity. ${ }^{3}$ In this study, the cross-linker reactivity is kept constant while the EEW and the viscosity are varied. The high viscosity and low epoxide equivalent weight resin DGEDP-Me was the most reactive with gel times at 52 and $25 \mathrm{~min}$ at 60 and $80^{\circ} \mathrm{C}$, respectively. Addition of NC-514 to prepare epoxy resin mixtures with DGEDP-Me results in large decreases in viscosity (Figure 1) while also diluting the epoxide content (Table 1). The onset of network formation at $60^{\circ} \mathrm{C}$ for $50 \%$ DGEDP-Me occurs at $84 \mathrm{~min}, 32 \mathrm{~min}$ longer than that for neat DGEDP-Me. This delay in network formation is due to the dilution of epoxide content in the mixture. However, by increasing the temperature to $80^{\circ} \mathrm{C}$, the gel times of neat DGEDP-Me and the $50 \%$ mixture are almost identical. This is due to the fact that the rise in mobility of the $50 \%$ composition with increased temperature is greater than that for neat DGEDP-Me. Consequently, the higher mobility of the $50 \%$ composition compensates for dilution in its epoxy content relative to neat DGEDP-Me. Further increase in the curing temperature to $100^{\circ} \mathrm{C}$ results in similar gel times for neat DGEDP-Me, neat NC-514 and the 50\% mixture. That the gel times during polymerizations of the three resins at temperatures above $80^{\circ} \mathrm{C}$ are almost temperature-independent is attributed to increased cross-linker reactivity and the convergence of viscosities to similarly low values ( $\leq 3$ Pa.s; Figure 1(b)).

\subsection{Fourier transform infrared spectroscopy and DSC}

The degree of cure for the resins was qualitatively determined to be relatively high by Fourier transform infrared spectroscopy and DSC. The oxirane signal intensity for the peak at $\sim 910 \mathrm{~cm}^{-1}$ for the uncured epoxy resins decreased dramatically after curing as is shown in supporting information 1 in the online supplementary data. Furthermore, modulated DSC was utilized, and only low-intensity non-reversible exothermal 
(a)

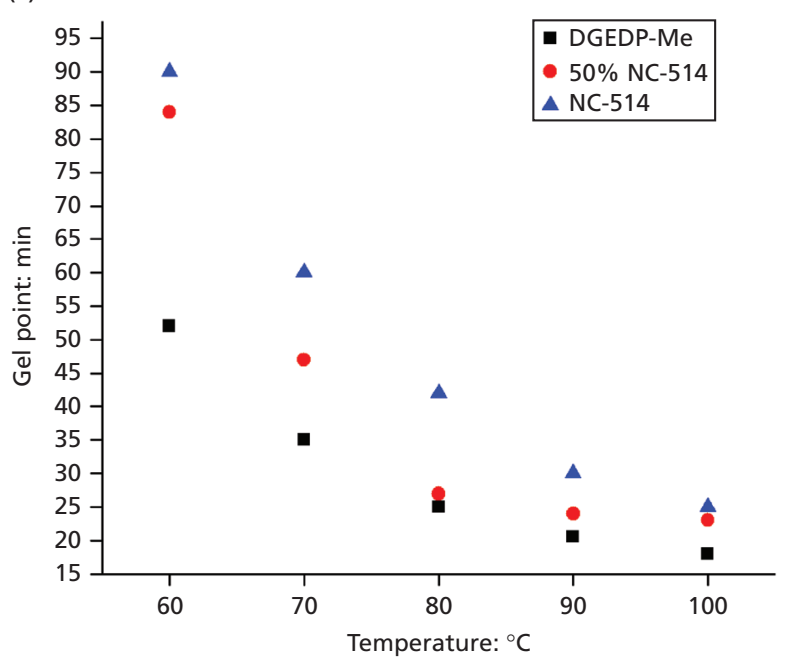

Figure 2. (a) Gel time at various isothermal temperatures to crosslink neat DGEDP-Me, NC-514 and a 1:1 (wt/wt) DGEDP-Me/NC-514 mixture of both resins with stoichiometric amounts of isophorone (b)

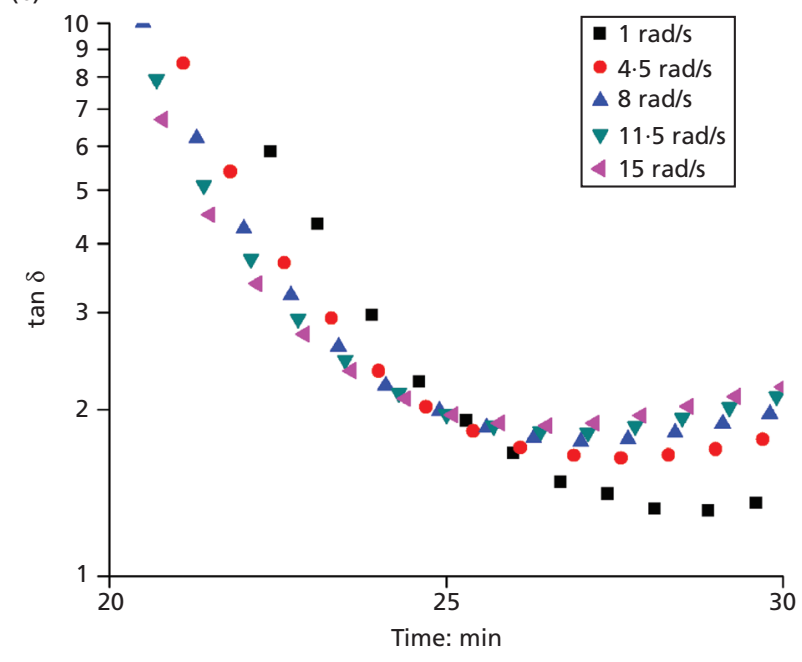

diamine cross-linker. (b) Plot of $\tan \delta$ against time from multifrequency time sweeps with intersection of the $\tan \delta$ plots representing the DGEDP-Me gel time at $70^{\circ} \mathrm{C}$ (a)

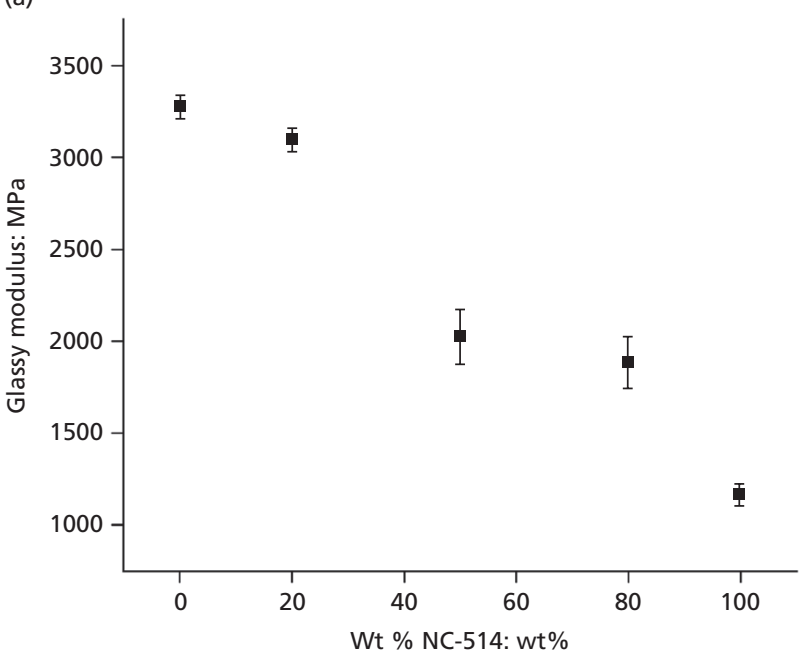

(b)

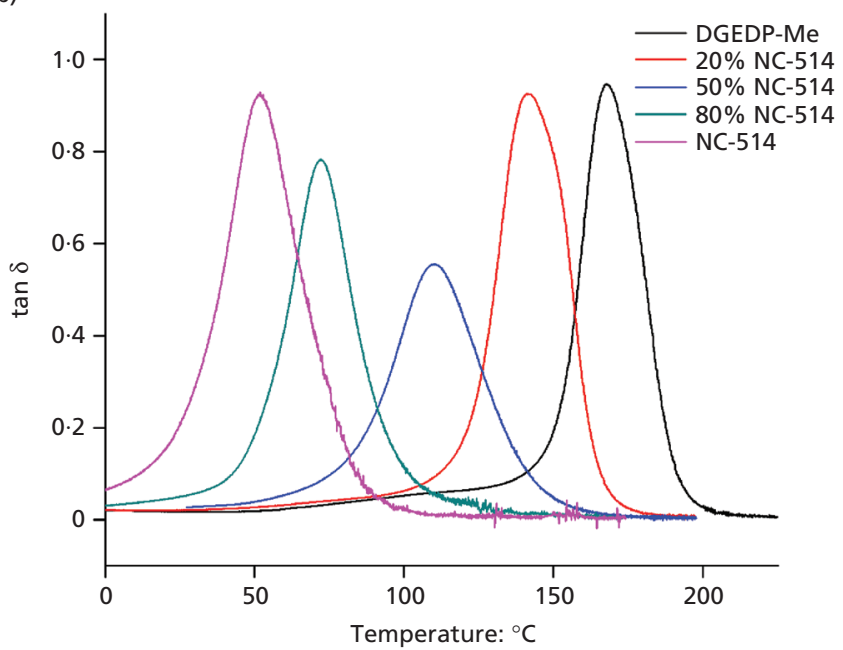

Figure 3. DMA analysis $\left(25^{\circ} \mathrm{C}\right)$ of the cured epoxy DGEDP-Me/ NC-514 resin series to determine the: (a) storage modulus ( $\left.E^{\prime}\right)$ from dual cantilever and (b) tan $\delta$ peaks from DMA dual cantilever

peaks were observed for the cured DGEDP-Me resin consistent with high extents of curing. No other non-reversible exothermal peaks were observed above the glass transition temperature by modulated DSC for DGEDP-Me/NC-514 mixtures or neat NC-514 (supporting information 2 in the online supplementary data).

\subsection{Dynamic mechanical analysis}

Dynamic mechanical analysis of cured resins provided information on relationships of the resin composition, the storage modulus and the glass transition temperature (by relating to the $T_{\alpha}$ ). A plot of the storage modulus $\left(25^{\circ} \mathrm{C}\right)$ as a function of wt $\%$-NC-514 is shown in Figure 3(a). The storage modulus of neat DGEDP-Me is $3300 \mathrm{MPa}$. By introducing 20 and $50 \mathrm{wt} \% \mathrm{NC}-514$, the storage modulus decreases to 3097 and $2025 \mathrm{MPa}$, respectively (7 and $39 \%)$. Nevertheless, the storage modulus of these epoxy resins are close to that of DGEBA $(2810 \mathrm{MPa}) .{ }^{35}$ Further increase in the NC-514 content to 80 and $100 \mathrm{wt} \%$ (neat NC-514) results in cured thermosets with storage modulus values of 1881 and $1162 \mathrm{MPa}$, respectively. The storage modulus of neat NC-514 reported in this 


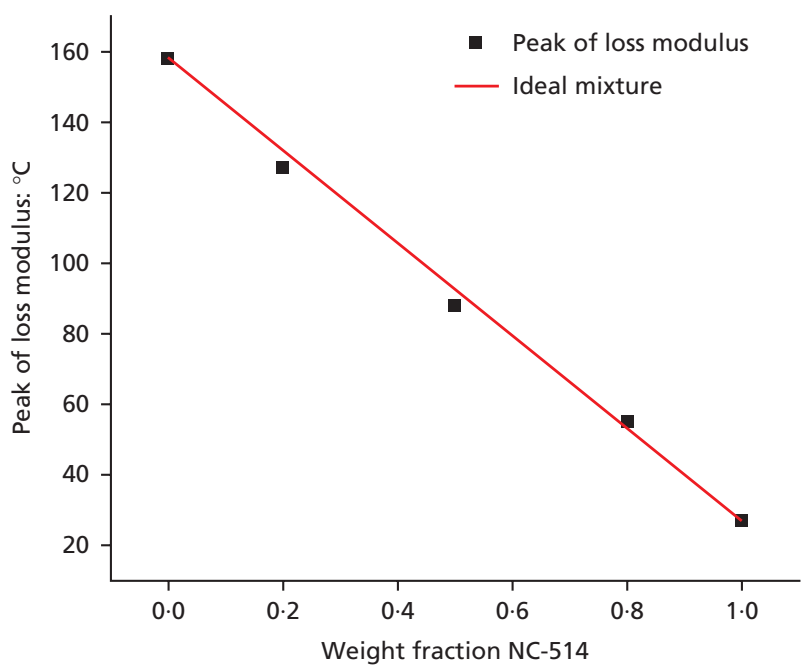

Figure 4. Comparison of the peak of the loss modulus (related to $T_{9}$ ) to predicted values for an ideal mixture (see Equation 5)

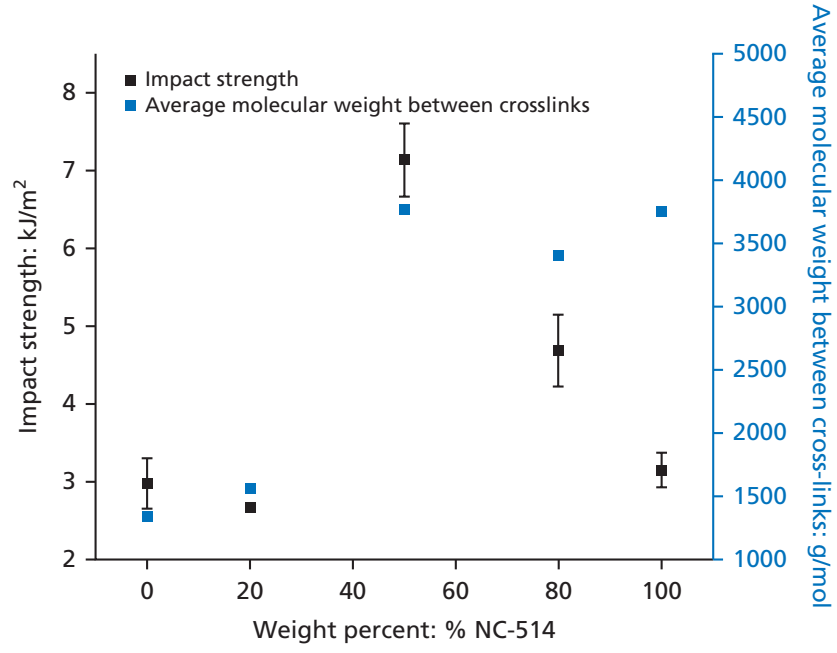

Figure 5. Plots displaying the dependence of both the average molecular weight between cross-links ( $M_{x^{\prime}}$ blue squares) and the notched Izod impact strength (black squares) on the NC-514 content of cured bio-based epoxy resins

paper is consistent with that reported by Jaillet et al. ${ }^{16}(1218 \mathrm{MPa}$ at $20^{\circ} \mathrm{C}$ ) using isophorone diamine as the cross-linker. Hence, increasing $\mathrm{wt} \%$-NC-514 in the cured epoxy resin mixtures results in less rigid materials as shown by the storage modulus at $25^{\circ} \mathrm{C}$ in Figure 3(a). This decrease is attributed to the increasing aliphatic content of the thermoset, and its significant deviation from a linear trend is most likely due to the presence in DGEDP-Me of $6 \mathrm{~mol} \%$ DGEDP-glycidyl ester coproduct. ${ }^{32}$ In other words, the three epoxy functionalities of DGEDP-glycidyl ester that result in relatively higher cross-link densities in cured resins skew the storage modulus to higher values. As the NC-514 content in the

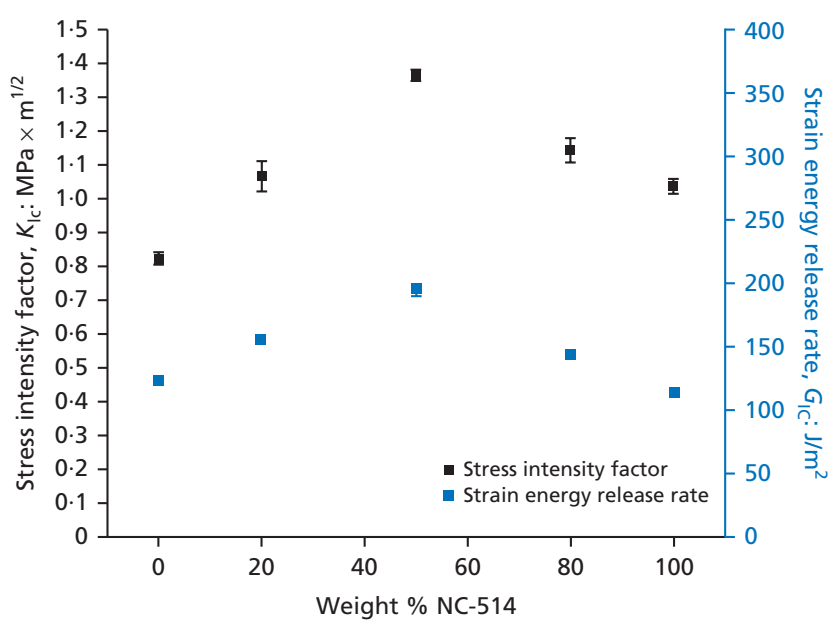

Figure 6. Mode I fracture toughness by three-point bending showing the critical stress intensity factor $\left(K_{\mathrm{I}}\right.$, black squares) and strain energy release rate $\left(G_{I C}\right.$, blue squares)

epoxy resins increases, DGEDP-glycidyl ester is diluted to values that have no substantial effects on cured resin properties. The storage modulus of the $\mathrm{NC}-514$ is not representative of the glassy modulus since the peak of the loss modulus is $27^{\circ} \mathrm{C}$ and the storage modulus was determined at $25^{\circ} \mathrm{C}$. Consequently, polymer chains between cross-links of the neat-NC-514 thermoset have some mobility resulting in flexible materials.

The alpha transition temperature $\left(T_{\alpha}\right)$ is closely related to the $T_{\mathrm{g}}$ and single peaks for the $\tan \delta$ (Figure 3(b)), and loss modulus (supporting information 3 in the online supplementary data) were observed implying that the distribution of DGEDP-Me and NC-514 units within the thermoset closely resembles a random distribution of each monomer. The $T_{\alpha} \approx T_{\mathrm{g}}$ was determined from peaks of the loss modulus $\left(E^{\prime \prime}\right)$, where the material softens from the glassy to rubbery state. A plot was constructed of DMA-determined $T_{\mathrm{g}}$ against the NC-514 weight fraction (Figure 4). This plot was compared to theoretical values generated by Equation 5 for ideal mixtures ${ }^{36}$ where

5. $\quad T_{\mathrm{g}}=T_{\mathrm{g} 1} w_{1}+T_{\mathrm{g} 2} w_{2}$

$T_{\mathrm{g}}$ is the glass transition temperature of the mixture, $T_{\mathrm{g} 1}$ is the glass transition temperature of cured DGEDP-Me, $T_{\mathrm{g} 2}$ is the glass transition temperature of cured NC-514, $w_{1}$ is the weight fraction of DGEDP-Me and $w_{2}$ is the weight fraction of NC-514.

Indeed, the experimental data in Figure 4 are in excellent agreement with calculated values derived from Equation 5 that describes an ideal mixture. This supports that epoxy resins DGEDP-Me and NC-514 are miscible over the compositions studied and that the resulting cross-linked copolymers have DGEDP-Me and NC-514 repeat units that are randomly distributed. This is likely due to 

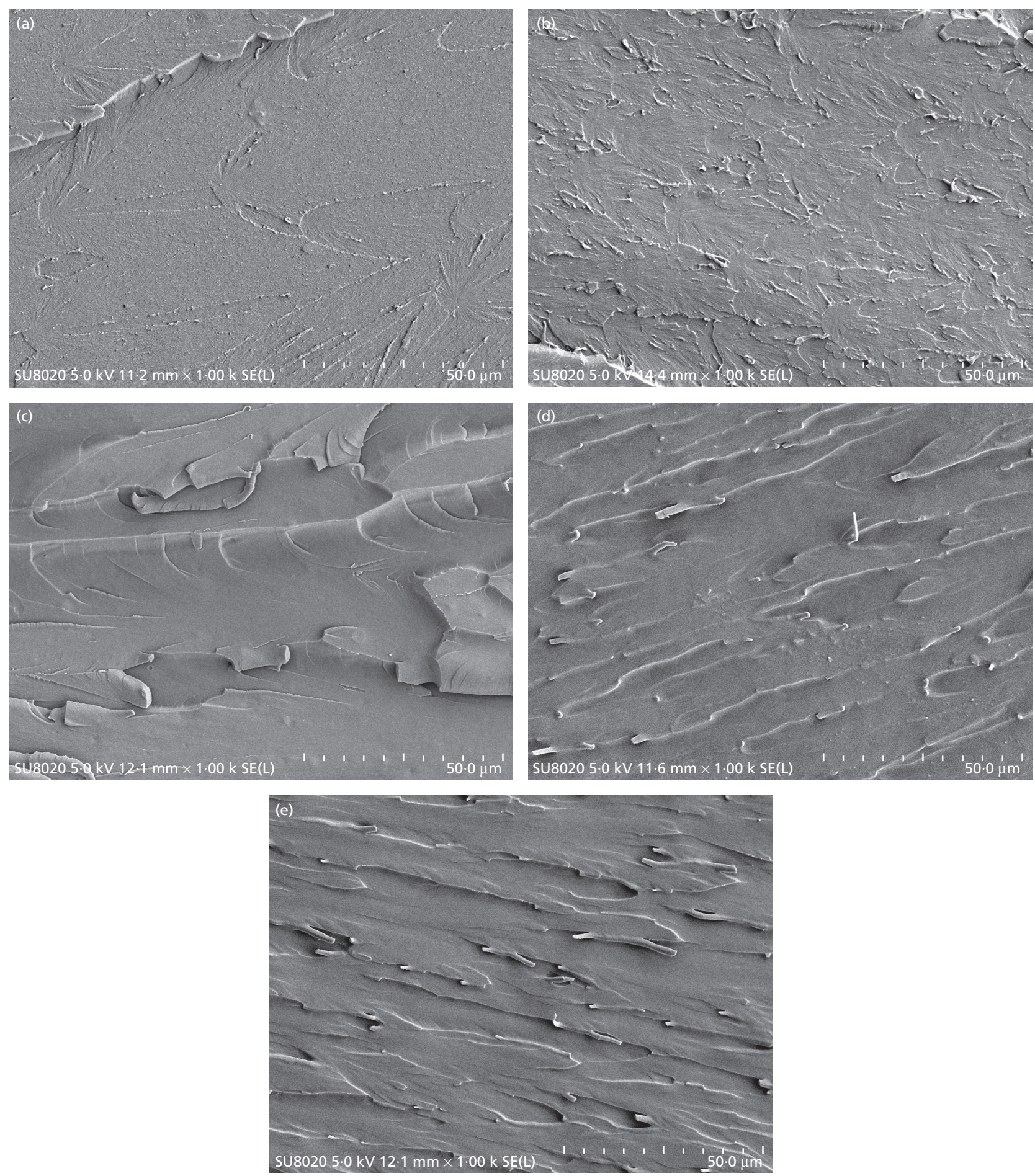

Figure 7. SEM of fractured surface after notched lzod impact test

of (a) neat NC-514, (b) 80 wt\% NC-514 (c) 50 wt\% NC-514, (d) 20

wt \% NC-514 (e) neat DGEDP-Me where scale bar is equal to $50 \mu \mathrm{m}$ 
that the reactivities of DGEDP-Me and NC-514 during thermoset formation are close in value which is consistent with that they both possess phenoxy glycidyl ether reactive moieties. Additionally, the resins are cured from the liquid state where the two components are miscible and have sufficient mobility to react at similar rates with isophorone diamine. Within the academic literature, systematic copolymerization of miscible epoxy resin systems is unexplored. From the analysis above, we propose that constructing a plot of the cured resin $T_{\mathrm{g}}$ against the weight fraction of the two liquid epoxy resin components will prove to be a generally useful approach in assessing the extent that cross-linked thermosets consist of randomly distributed epoxy resin building blocks (e.g. relative reactivity of liquid epoxy resins).

Glass transition temperatures of thermosets are primarily determined by three factors: $(a)$ the rigidity of polymer chain segments (e.g. vegetable oil, isosorbide, bisphenol, etc.) between cross-links, $(b)$ the cross-link density which is related to the molecular weight between cross-links $\left(M_{\mathrm{x}}\right)$ and $(c)$ the intermolecular forces between polymer chains (hydrogen bonding, van der Waals forces, etc). NC-514 possesses about double the epoxide equivalent weight relative to DGEDP-Me. Hence, increasing the NC-514 content in mixtures not only increases chain flexibility, but also reduces the cross-link density (e.g. increases in the average molecular weight between cross-links, $M_{\mathrm{x}}$ ). Additionally, the NC-514 possesses less phenolic functionality and overall decreased propensity for weak intermolecular bonding. To determine $M_{\mathrm{x}}$ for thermosets prepared from DGEDP-Me/NC-514 mixtures, measurements of the shear modulus by oscillatory rheology in the rubbery region of the thermosets (peak of the $\tan \delta+50^{\circ} \mathrm{C}$ ) were performed and analyzed by Equation 6 from rubbery elasticity theory

$$
\text { 6. } M_{\mathrm{x}}=\frac{\rho R T}{G_{\mathrm{N}}}
$$

where $\rho$ is density (densities determined by ASTM D792-13 were all $\left.1 \mathrm{~g} / \mathrm{cm}^{3}\right), R$ is the universal gas constant, $G_{\mathrm{N}}$ is the shear modulus and $T$ is the temperature at the peak of the $\tan \delta+50^{\circ} \mathrm{C}$ in Kelvin. ${ }^{37}$ The shear modulus was determined from oscillatory rheology by averaging frequency-independent $G^{\prime}$ values as shown in supporting information 4 in the online supplementary data. Figure 3(a) shows the plot of $G_{\mathrm{N}}$ as a function of NC-514 wt $\%$ in the epoxy resin mixture.

A plot was constructed to determine the relationship between the wt\% NC-514 and $M_{\mathrm{x}}$ (Figure 5). Increase in the NC-514 content in the epoxy resin mixture from 20 to $50 \mathrm{wt} \%$ resulted in large increase in $M_{\mathrm{x}}$ from 1500 to $3800 \mathrm{~g} / \mathrm{mol}$. Values of $M_{\mathrm{x}}$ at 50,80 and $100 \mathrm{NC}-514$ are 3800,3400 and $3800 \mathrm{~g} / \mathrm{mol}$, respectively. This small variation in $M_{\mathrm{x}}$ values at $\geq 50 \%$ NC-514 indicates that $M_{\mathrm{x}}$ plateau's in this range of compositions. Nevertheless, within this plateau region from 50 to $100 \% \mathrm{NC}-514$, the content of aliphatic units continues to increase. This rise in aliphatic NC-514 units relative to rigid DGEDP-Me units, theoretically, should correlate with an increase in material toughness due to increased chain mobility which, in turn, should increase the ability of the material to absorb energy. With the exception of $100 \%$ NC-514 thermoset resins, the $T_{\mathrm{g}}$ is above ambient conditions.

\subsection{Toughness: impact strength and three-point bending}

Impact testing is one method to investigate the toughness of thermoset polymers under high strain rates. The notched Izod impact strength of cured DGEDP-Me/NC-514 epoxy resins was determined, and the values are plotted along with $M_{\mathrm{x}}$ values as a function of the wt $\%$ NC-514 (Figure 5). The impact strength of cured neat DGEDP-Me epoxy resin is relatively low $\left(3.0 \mathrm{~kJ} / \mathrm{m}^{2}\right)$ and similar in value to the cured neat NC-514 epoxy resin $\left(3 \cdot 2 \mathrm{~kJ} / \mathrm{m}^{2}\right)$. Thus, the impact strength of the two compositional extremes (e.g. the high-modulus brittle cured DGEDP-Me epoxy resin and the cured flexible NC-514 epoxy resin) are nearly equal. Incorporation of 20\% NC-514 in the liquid DGEDP-Me/NC-514 mixture resulted in a 10\% decrease in the impact strength relative to the neat DGEDP-Me cured resin. Further increase in the NC-514 content to $50 \mathrm{wt} \%$ resulted in an increase in the impact strength from 3.2 to $7 \cdot 14 \mathrm{~kJ} / \mathrm{m}^{2}$ (2.2-fold increase). This improvement in impact strength correlates with an increase in $M_{\mathrm{x}}$ from 1500 to $3800 \mathrm{~g} / \mathrm{mol}$ (see above). At $80 \mathrm{wt} \%$ $\mathrm{NC}-514$, the impact strength is roughly intermediate $\left(4.7 \mathrm{~kJ} / \mathrm{m}^{2}\right)$ between the values of the $50 \%$ composition and those of the neat resins while $M_{\mathrm{x}}$ remained relatively constant from 50 to $100 \%$ NC-514. Thus, the $50 \%$ resin composition attains a balance between rigid and more flexible segments with an extended average molecular weight between cross-links that results in important improvements in the cured epoxy resin impact strength. Additionally, the decrease in impact strength at higher NC-514 content was unexpected, and we hypothesize that it is due to decreased modulus (Figure 3(a)) while the $M_{\mathrm{x}}$ stays relatively constant (Figure 5). Thus, increased epoxy resin toughness is not a consequence of simply increasing epoxy resin ductility.

Three-point bending of a single edge notched specimens was conducted to gain insight to the fracture toughness of the prepared materials and to confirm the results from the notched Izod impact testing. Plots of experimentally determined values of the stress intensity factor and strain energy release rate as a function of the wt $\%$ NC-514 in cured epoxy resins are shown in Figure 6. The stress intensity factor $\left(K_{\mathrm{IC}}\right)$ increased from 0.82 to $1.06 \mathrm{MPa} \cdot \mathrm{m}^{1 / 2}$ with addition of $20 \mathrm{wt} \% \mathrm{NC}-514$. The $50 \mathrm{wt} \%$ epoxy resin composition has the highest $K_{\mathrm{IC}}\left(1 \cdot 40 \mathrm{MPa} \cdot \mathrm{m}^{1 / 2}\right)$, a $70 \%$ increase relative to the cured neat DGEDP-Me epoxy resin. Further increase in the NC-514 content in epoxy resin mixtures resulted in decreased toughness following a similar trend to that of the notched Izod impact strength. Values of $G_{\text {IC }}$ followed a similar trend as those of $K_{\mathrm{IC}}$. Accordingly, the $G_{\mathrm{IC}}$ for neat DGEDP-Me is $120 \mathrm{~J} / \mathrm{m}^{2}$ and it increased by $62 \%$ for the $50 \mathrm{wt} \%$ NC-514 composition. 
Bio-based epoxy resin toughening

Maiorana et al.
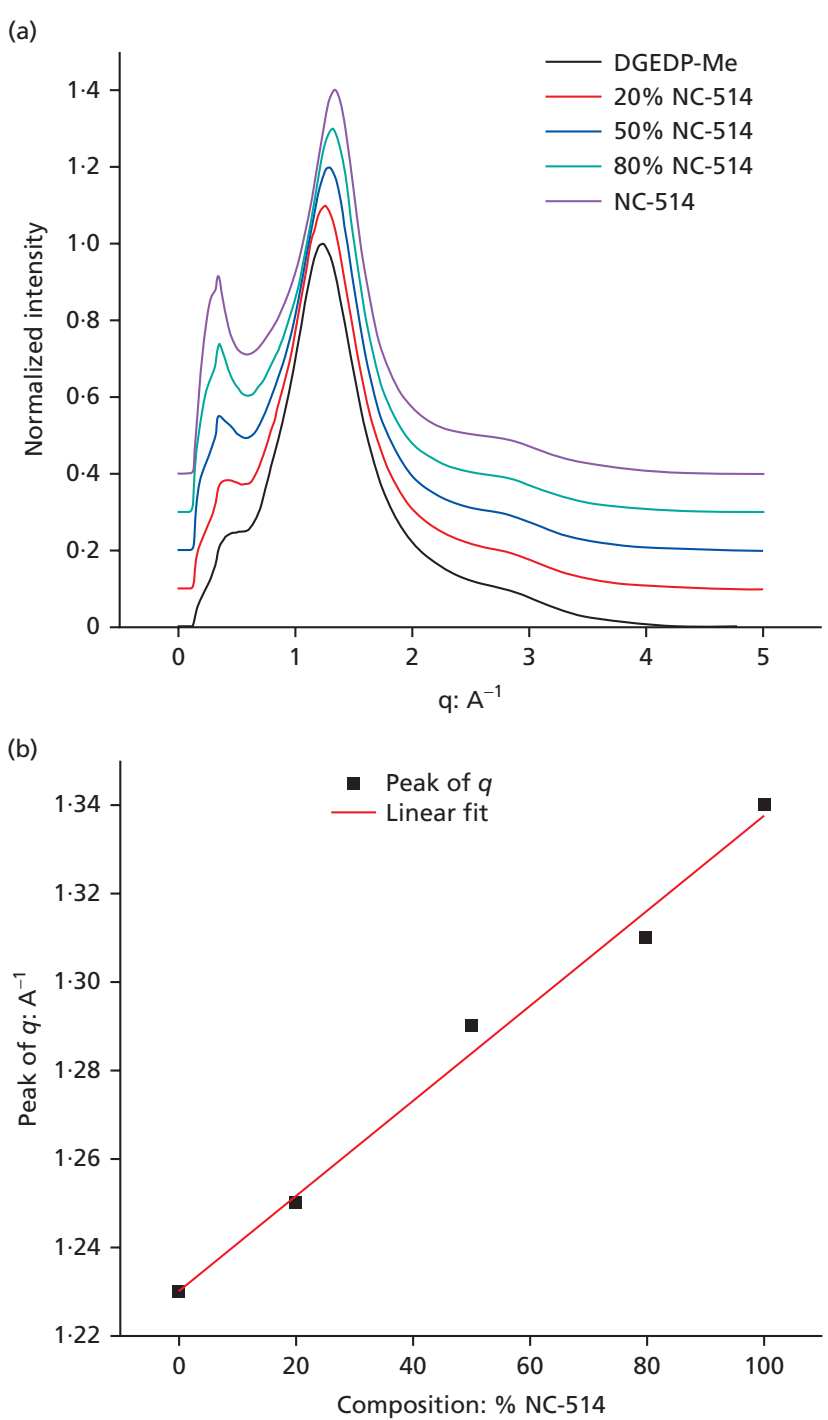

Figure 8. Small-angle X-ray scattering of the prepared thermoset copolymers (a) offset normalized intensity plotted against $q$ and (b) the peak of $q$ plotted against percent composition fitted with a linear function

From the above, toughening of the DGEDP-Me/NC-514 epoxy resin system was achieved by copolymerization of a lower EEW stiff epoxy resin (DGEDP-Me) with a higher EEW flexible epoxy resin. The resulting one-phase system enabled fine-tuning of the molecular weight between cross-links and chain ductility, critical parameters in optimizing epoxy resin modulus and impact strength. The toughening results obtained herein $\left(K_{\mathrm{IC}}=1.37 \mathrm{MPa} \cdot \mathrm{m}^{1 / 2}\right.$ for $50 \mathrm{wt} \% \mathrm{NC}-514)$ are similar to BPA epoxy resins toughened with low loadings of rubbery phase separated polymers $\left(K_{\mathrm{IC}}=\right.$ $\left.0 \cdot 91-2 \cdot 0 \mathrm{MPa} \cdot \mathrm{m}^{1 / 2}\right)$ at rubber loadings ranging from 0 to $20 \% .{ }^{11,38,39}$ Furthermore, cured DGEDP-Me/NC-514 in a 1:1 weight ratio is tougher than BPA epoxies where extension of the molecular weight between cross-links was achieved using BPA chain extenders. ${ }^{40}$
Moreover, the impact strength of cured DGEDP-Me/NC-514 epoxy resins and those that use rubber toughening show similar trends as there is an optimal concentration of NC-514 and rubber particles, respectively, to achieve maximal toughening. ${ }^{19,41,42}$ In other words, rubber toughening at high loadings also decreases the modulus and material toughness. The strategy explored herein for toughening of DGEDP epoxy resins allows for further optimization by simultaneous manipulation of both the polymer chain composition and the content of a rubber toughening agent that is added to the system. Indeed, current work is underway to explore the interplay between variation in NC-514 and a rubber toughening agent.

\subsection{Morphology}

The fractured surfaces from notched Izod impact testing of cured neat DGEDP-Me, neat NC-514 and DGEDP-Me/NC-514 epoxy resin mixtures were analyzed by scanning electron microscopy (SEM) (Figure 7 and supporting information 5 in the online supplementary data). The SEM images illustrate that each epoxy resin composition has one-phase morphology. This agrees with DMA analyses where each resin composition has a single $\tan \delta$ peak (Figure 3(b)). The fractured surfaces of neat NC-514 and $80 \mathrm{wt} \%$ NC-514 are relatively smooth in comparison to neat DGEDP-Me and the $20 \mathrm{wt} \%$ NC-514 composition (Figure 7 and supporting information 5 in the online supplementary data). The neat and $80 \mathrm{wt} \%$ NC-514 fractured surfaces exhibit ellipsoidal conical plastic deformations on their surfaces, and the deformation size is smaller for the $80 \mathrm{wt} \%$ NC-514 (20 wt\% DGEDP-Me) mixture. The fractured surfaces of ductile epoxy resins is unexplored in the literature. The large conical ellipsoidal deformations are attributed to void coalescence for neat NC-514 that is hindered in the $80 \mathrm{wt} \%$ NC-514 mixture. Additionally, the surface roughness increases from neat NC-514 to $80 \mathrm{wt} \% \mathrm{NC}-514 .^{43}$

Neat DGEDP-Me and the $20 \mathrm{wt} \%$ NC-514 mixture exhibited morphologies that are consistent with brittle epoxy thermoset resins. ${ }^{44}$ The fractured surfaces have sharp conical deformations, and the deformation size is larger for $20 \mathrm{wt} \% \mathrm{NC}-514$. The conical deformation is indicative of a brittle epoxy resin fractured surface. ${ }^{45}$ The broadening of the conical fractures for $20 \mathrm{wt} \% \mathrm{NC}-514$ relative to neat DGEDP-Me is consistent with experimental findings discussed above that show the matrix is gaining in ductility ${ }^{46}$ and has increased toughness (e.g. Figure 6).

Figure 7 also shows the fractured surface of the cured $50 \mathrm{wt} \%$ NC-514 mixture. The large conical or ellipsoidal deformations observed are remarkably different than the other resin compositions. As discussed above, based on its impact strength and $K_{\mathrm{IC}}$ values (Figures 5 and 6), the $50 \mathrm{wt} \% \mathrm{NC}-514$ cured epoxy resin has greater toughness than the other resin compositions studied herein. Since cured resin mixtures with related compositions to those studied here have not yet been systematically studied, additional work will be needed to interpret further the differences between the fracture surfaces of cured DGEDP-Me/NC-514 epoxy resins. 


\subsection{Small-angle X-ray scattering}

Small-angle X-ray scattering was used to further assess the potential for macroscopic morphological changes of the thermoset polymers. No diffraction patterns in the range of $q<1$ were observed. Consequently, an image plate was used to capture the wider angle diffraction patterns. Inspection of Figure 8(a) shows that peaks with $q$ from 1.23 to $1.34 \mathrm{~A}^{-1}$ shifts to higher values with increased NC-514 content in the cured epoxy resin. The plot in Figure 8(b) shows that the peak of $q$ increases linearly with increasing NC-514 content in the cured epoxy resins. The peak of $q$ shown in Figure 8(a) is further indicative of a disordered polymer structure. Furthermore, the linear trend in shifts observed for peaks with $q$ from 1.23 to $1.34 \mathrm{~A}^{-1}$ further corroborates the random distribution of epoxy monomers in the cured resins. This analysis supports that the large change in the average molecular weight between cross-links observed in Figure 5 is not due to macroscopic phase separation. Future work by the authors' laboratory is planned to comprehensively investigate related epoxy resin systems determining relative reactivity's of component epoxy resins and the potential for phase separation as a function of curing temperature.

\subsection{Thermal gravimetric analysis}

The thermal stability of the cured neat DGEDP-Me, neat NC-514 and DGEDP-Me/NC-514 epoxy resin mixtures was studied by thermal gravimetric analysis under constant $\mathrm{N}_{2}$ flow. The temperatures at which the onset of degradation occurs at weight losses of 3, 5 and 10 wt $\%\left(T_{3 \%}, T_{5 \%}\right.$ and $\left.T_{10 \%}\right)$ were determined (supporting information 6 in the online supplementary data). The values of $T_{\mathrm{d} 5 \%}$ for neat DGEDP-Me, 50\% NC-514 and neat NC-514 are 324, 525 and $335^{\circ} \mathrm{C}$, respectively, demonstrating that the thermal stability of the resin series is high and varied little with composition. Furthermore, small changes observed in thermal stability as a function of the resin composition were non-systematic and, consequently, could not be correlated with cured epoxy resin structure. However, the \%-char remaining at $600^{\circ} \mathrm{C}$ did vary systematically $(12,9,6,1$ and 0.8 for neat DGEDP-Me, 20\% NC-514, 50\% NC-514, 80\% NC-514 and $100 \%$ NC-514, respectively). This trend is attributed to increasing content of aromatic-substituted phenolic moieties contributed by the DGEDP-Me epoxy resin and results in higher char amounts.

\subsection{Mechanism of toughening}

The following discusses previous studies on epoxy resin toughening in an effort to gleam further insights into the structure-property relationships observed herein. In 1970, Bell reported that variation of the molecular weight between cross-links of epoxy resins did not alter the tensile properties but that the notched Izod impact followed a parabolic type curve. However, Bell ${ }^{28}$ did not provide a clear explanation of the toughening mechanism. Subsequently, Pearson and Yee $^{29}$ using DGEBA oligomers reported small increases in toughening of neat resins by increasing the molecular weight between crosslinks. However, by incorporating a rubber additive, the corresponding rubber-modified epoxies showed large increases in fracture toughness with increasing epoxide resin molecular weight. ${ }^{29}$ They attributed increased toughening to the yielding ability of the polymer matrix. By decreasing the cross-link density in the presence of the soft elastomeric additive, the epoxies exhibited greater ductility and, consequently, greater toughness. Furthermore, the ability of the matrix to shear band, cold draw and shear yield directly related to the amount of energy that can be dissipated by the matrix. Also, voiding and shear banding were identified as energy dissipative processes. In contrast, herein, the density of cross-links from 50 to $100 \mathrm{wt} \%$ NC-514 remained nearly constant (Figure 5), while the storage modulus (Figure 3(a)) decreased due to increased ductility of chains, and consequently, the material toughness decreased. ${ }^{31}$ Crawford and Lesser further tested the assumption that the molecular weight between cross-links is important for epoxy thermoset toughening. They found that, as the molecular weight between cross-links increases, tougher materials were obtained. Furthermore, in agreement with Pearson and Yee, ${ }^{29}$ they attributed toughening to an increased ability of the matrix to yield in front of the crack tip. Liu et al. ${ }^{39,40}$ also reported only small increases in polymer toughness as the molecular weight between cross-links was extended. By introducing a unique phase separating diblock copolymer within the cross-linked matrix that functions as a rubbery phase, Liu et al. ${ }^{39,40}$ were also able to achieve large increases in epoxy toughness. The unique aspect of the approach disclosed herein is that toughening was achieved without addition of a separate rubbery phase. Furthermore, toughness did not continue to increase as the density of matrix crosslinks was decreased. Instead, the content of NC-514 in DGEDP-Me/ NC-514 epoxy resin mixtures was manipulated such that both chain ductility and molecular weight between cross-links concurrently increased. This resulted in higher toughness than extension with BPA. However, unlike extension of the molecular weight with BPA moieties, at high amounts of the ductile resin component (NC-514), losses in polymer toughness resulted. Furthermore, comparison of this work with that reported previously demonstrates that introducing ductile units for chain extension has benefits over chain extension by BPA units since, for the latter, chains between cross-links remain rigid which limits energy dissipation by the matrix.

\section{Summary of results}

This paper demonstrates that by introducing controlled quantities of a flexible bio-based epoxy resin (NC-514) to a rigid bio-based epoxy resin (DGEDP-Me), mixture compositions can be identified that result in both important reduction in the epoxy resin viscosity and toughening of the corresponding cured epoxy material. Analysis showed that thorough mixing of the two epoxy resins well before curing allowed for a one-phase cross-linked network with random distributions of each component. Also, by varying the ratio of NC-514 content in epoxy resin mixtures, precise control of epoxy resin mixture viscosity was achieved. Furthermore, by combining NC-514 with DGEDP-Me, intermolecular forces present in neat DGEDP-Me that were responsible for its high viscosity were disrupted, and the activation energy of flow decreased. Dilution of the epoxide equivalent weight of the mixture with addition of NC-514 also influenced the 
curing behavior of the resins by delaying network formation at lower temperatures. Glass transition temperatures of cured DGEDP-Me/ NC-514 mixtures followed a linear trend indicating that the distribution of repeat units within the cross-linked resin is approximately random. The decrease in storage modulus with increased NC-514 content is attributed to the increasing aliphatic nature of the thermoset materials. Furthermore, variation in the molecular weight between cross-links was confined to a narrow range since DGEDP-Me and NC-514 have similar EEW values (215 and 490, respectively).

The toughness of cured mixtures was highest when DGEDP-Me/ NC-514 was 50/50 (wt/wt). At this composition, the molecular weight between cross-links reached the highest value, while the storage modulus remained relatively high. Further increases of NC-514 above $50 \mathrm{wt} \%$ resulted in decreased toughness due to reductions in the matrix modulus, while the molecular weight between cross-links remained nearly constant. Thus, in this work, matrix toughening was achieved by concurrently manipulating matrix chain rigidity by adjusting the ratio of ductile and rigid matrix components and the molecular weight between cross-links. The toughening mechanism is fundamentally different from those reported in other studies since a separate rubbery phase was not needed. Instead, matrix toughening results from extension of the molecular weight between cross-links and by adjusting the chain rigidity.

\section{Acknowledgments}

The authors thank the Cardolite Corporation for their kind donation of Cardolite NC-514, UMONS for SEM analyses and Joel Morgan at Rensselaer Polytechnic Institute for assistance in the small-angle $\mathrm{X}$-ray scattering.

The authors are grateful for funding received from the National Science Foundation Partnerships for International Research and Education Program (Award \#1243313).

\section{REFERENCES}

1. Reichwein, H.; Langemeier, P.; Hasson, T.; Schendzielorz, M. Proceedings of the 10th-Annual SPE Automotive Composites Conference \& Exhibition 2010, 1-20.

2. Sørensen, P. A.; Kiil, S.; Dam-Johansen, K.; Weinell, C. E. Anticorrosive coatings: a review. Journal of Coatings Technology and Research 2009, 6, 135-176.

3. Pham, H. Q.; Marks, M. J. Epoxy resins. In Ullmann's Encyclopedia of Industrial Chemistry, Electronic Release (Elvers, B. (ed.). Weinheim, Germany: Wiley-VCH, 2012, 155-244.

4. Chen, M.-Y.; Ike, M.; Fujita, M. Acute toxicity, mutagenicity, and estrogenicity of bisphenol-A and other bisphenols. Environmental Toxicology 2002, 17, 80-86.

5. Maffini, M. V.; Rubin, B. S.; Sonnenschein, C.; Soto, A. M. Endocrine disruptors and reproductive health: the case of bisphenol A. Molecular and Cellular Endocrinology 2006, 254, 179-186.
6. Steinmetz, R.; Brown, N. G.; Allen, D. L.; Bigsby, R. M.; Ben-Jonathan, N. The environmental estrogen bisphenol A stimulates prolactin release in vitro and in vivo. Endocrinology 1997, 138, 1780-1786.

7. Nelson, A. M.; Long, T. E. A perspective on emerging polymer technologies for bisphenol-A replacement. Polymer International 2012, 61, 1485-1491.

8. Blair, R. M.; Fang, H.; Branham, W. S.; Hass, B. S.; Dial, S. L.; Moland, C. L.; Tong, W.; Shi, L.; Perkins, R.; Sheehan, D. M. The estrogen receptor relative binding affinities of 188 natural and enochemicals: structural diversity of ligands. Toxicological Sciences 2000, 54, 138-153.

9. Okada, H.; Tokunaga, T.; Liu, X.; Takayanagi, S.; Matsushima, A.; Shimohigashi, Y. Direct evidence for revealing structural elements essential for the high binding ability of the bisphenol A to human estrogen-related receptor. Environmental Health Perspectives 2008, 116, 32-38.

10. Auvergne, R.; Caillol, S.; David, G. Biobased thermosetting epoxy: present and future. Chemical Reviews 2014, 114, 1082-1115.

11. Łukaszczyk, J.; Janicki, B.; Kaczmarek, M. Synthesis and properties of isosorbide based epoxy resin. European Polymer Journal 2011, 47, 1601-1606.

12. Aouf, C.; Lecomte, J.; Villeneuve, P.; Dubreucq, E.; Fulcrand, $\mathrm{H}$. Chemo-enzymatic functionalization of gallic and vanillic acids: synthesis of bio-based epoxy resins prepolymers. Green Chemistry 2012, 14, 2328-2336.

13. Aouf, C.; Nouailhas, H.; Fache, M.; Caillol, S.; Boutevin, B.; Fulcrand, H. Multi-functionalization of gallic acid. Synthesis of a novel bio-based epoxy resin. European Polymer Journal 2013, 49, 1185-1195.

14. Ittara, S.; Sarangapani, K. Process for Preparing Polyurethane Polyol and Rigid Foams Therefrom From Cardanol. US Patent 2006/0004115A1, Jan. 5, 2006.

15. Dai, Z.; Dalal, A.; Lawson, C. I.; He, J. Cardanol Based Dimers and Uses Therefor. US patent 8,415,446 B2, Apr. 9, 2013.

16. Jaillet, F.; Darroman, E.; Ratsimihety, A.; Auvergne, R.; Boutevin, B.; Caillol, S. New biobased epoxy materials from cardanol. European Journal of Lipid Science and Technology 2014, 116, 63-73.

17. Unnikrishnan, K. P.; Thachil, E. T. Synthesis and characterization of cardanol-based epoxy systems. Designed Monomers and Polymers 2008, 11, 593-607.

18. Ratna, D.; Banthia, A. Rubber toughened epoxy. Macromolecular Research 2004, 12, 11-21.

19. Thomas, R.; Yumei, D.; Yuelong, H.; Le, Y.; Moldenaers, P.; Weimin, Y.; Czigany, T.; Thomas, S. Miscibility, morphology, thermal, and mechanical properties of a DGEBA based epoxy resins toughened with a liquid rubber. Polymer (Guildf). 2008, 49, 278-294.

20. Liu, J. D.; Sue, H.-J.; Thompson, Z. J.; Bates, F. S.; Dettloff, M.; Jacob, G.; Verghese, N.; Pham, H. Strain rate effect on toughening of nano-sized PEP-PEO block copolymer modified epoxy. Acta Materialia 2009, 57, 2691-2701. 
21. Raghavachar, R.; Letasi, R.; Kola, P. J. Rubber-toughening epoxy thermosets with epoxidized crambe oil. Journal of the American Oil Chemists' Society 1999, 76, 511-516.

22. Schrotz, M. Thermosettable Composite Containing a Glycidyl Ether Based on Timethyolpropane Octadecaethoxilate. European patent EP2403892 A1, Jan. 11, 2012.

23. Declet-Perez, C.; Redline, E.; Francis, L. F.; Bates, F. S. Role of localized network damage in block copolymer toughened epoxies. ACS Macro Letters 2012, 1, 338-32.

24. Thompson, Z. J.; Hillmyer, M. A.; Liu, J. D.; Sue, H.; Dettloff M.; Bates, F. S. Block copolymer toughened epoxy: role of cross-link density. Macromolecules 2009, 42, 2333-2335.

25. Thio, Y.; Wu, J.; Bates, F. J. The role of inclusion size in toughening of epoxy resins by spherical micelles. Journal of Polymer Science Part B: Polymer Physics 2009, 47, 1125-1129.

26. Hillmyer, M.; Lipic, P. J. Self-assembly and polymerization of epoxy resin-amphiphilic block copolymer nanocomposites. Journal of the American Chemical Society 1997, 7863, 2749-2750.

27. Grubbs, R.; Dean, J.; Broz, M.; Bates, F. Reactive block copolymers for modification of thermosetting epoxy. Macromolecules 2000, 33, 9522-9534.

28. Bell, J. J. Mechanical properties of a glassy epoxide polymer: effect of molecular weight between crosslinks. Journal of Applied Polymer Science 1970, 14, 1901-1906.

29. Pearson, R. A.; Yee, A. F. J. Toughening mechanisms in elastomer-modified epoxies. Journal of Materials Science 1989, 24, 2571-2580.

30. Levita, G.; Petris, S. D.; Marchetti, A.; Lazzeri, A. J. Crosslink density and frature toughness of epoxy resins. Journal of Materials Science 1991, 26, 2348-2352.

31. Crawford, E.; Lesser, A. J. The effect of network architecture on the thermal and mechanical behavior of epoxy resins. Journal of Polymer Science Part B: Polymer Physics 1998, 36, 1371-1382.

32. Maiorana, A.; Spinella, S.; Gross, R. A. Bio-based alternative to the diglycidyl ether of bisphenol A with controlled materials properties. Biomacromolecules 2015, 16, 1021-1031.

33. Garcia, F.; Soares, B. J. Mechanical properties of epoxy networks based on the DGEBA and aliphatic amines. Journal of Applied Polymer Science 2007, 106, 2047-2055.

34. Holly, E. E.; Venkataraman, S. K.; Chambon, F.; Henning Winter, H. J. Fourier transform mechanical spectroscopy of viscoelastic materials with transient structure. Journal of Non-Newtonian Fluid Mechanics 1988, 27, 17-26.

35. Nouailhas, H.; Aouf, C.; Guerneve, C. L.; Caillol, S.; Boutevin, B.; Fulcrand, H. J. Synthesis and properties of biobased epoxy resins. Part 1. Glycidylation of flavonoids by epichlorohydrin. Journal of Polymer Science Part A: Polymer Chemistry 2011, 49, 2261-2270.

36. Sperling, L. H. Introduction to Physical Polymer Science. Weinheim, Germany: Wiley-Interscience, 2005, 399-404.

37. Flory, P. J. Principles of Polymer Chemistry. New York, NY, USA: Cornell University Press, 1953.
38. Wu, J.; Thio, Y. S.; Bates, F. S. The role of inclusion size in toughening of epoxy resins by spherical micelles. Journal of Polymer Science Part B: Polymer Physics 2005, 43, 1950-1965.

39. Liu, J. D.; Thompson, Z. J.; Sue, H.-J.; Bates, F. S.; Hillmyer, M. a.; Dettloff, M.; Jacob, G.; Verghese, N.; Pham, H. Toughening of epoxies with block copolymer micelles of wormlike morphology. Macromolecules 2010, 43, 7238-7243.

40. Liu, J. D.; Sue, H.-J.; Thompson, Z. J.; Bates, F. S.; Dettloff, M.; Jacob, G.; Verghese, N.; Pham, H. Effect of crosslink density on fracture behavior of model epoxies containing block copolymer nanoparticles. Polymer (Guildf). 2009, 50, 4683-4689.

41. Le, Q.-H.; Kuan, H.-C.; Dai, J.-B.; Zaman, I.; Luong, L.; Ma, J. Structure-property relations of $55 \mathrm{~nm}$ particle-toughened epoxy. Polymer (Guildf). 2010, 51, 4867-4879.

42. Ratna, D.; Simon, G. Mechanical characterization and morphology of carboxyl randomized poly (2-ethyl hexyl acrylate) liquid rubber toughened epoxy resins. Polymer (Guildf). 2001, 42, 7739-7747.

43. Pfaff, F. A. Growing more ductile epoxies: an essential work of fracture study. Journal of Coatings Technology and Research 2007, 4, 151-159.

44. Hernández-Pérez, a.; Avilés, F.; May-Pat, a.; ValadezGonzález, a.; Herrera-Franco, P. J.; Bartolo-Pérez, P. Effective properties of multiwalled carbon nanotube/epoxy composites using two different tubes. Composites Science and Technology 2008, 68, 1422-1431.

45. Fiedler, B.; Hojo, M.; Ochiai, S.; Schulte, K.; Ando, M. Failure behavior of an epoxy matrix under different kinds of static loading. Composites Science and Technology 2001, 61, 1615-1624.

46. Wenbo, L.; Tingqing, Y. J. Computer simulation of conicshaped patterns on fracture surfaces of polymers. Journal of Applied Polymer Science 2003, 89, 1722-1725.

WHAT DO YOU THINK?

To discuss this paper, please email up to 500 words to the managing editor at gmat@icepublishing.com

Your contribution will be forwarded to the author(s) for a reply and, if considered appropriate by the editor-inchief, will be published as a discussion in a future issue of the journal.

ICE Science journals rely entirely on contributions sent in by professionals, academics and students coming from the field of materials science and engineering. Articles should be within 5000-7000 words long (short communications and opinion articles should be within 2000 words long), with adequate illustrations and references. To access our author guidelines and how to submit your paper, please refer to the journal website at www.icevirtuallibrary.com/gmat 